\title{
ANALISIS BILINGUALISME PADA NOVEL SUPERNOVA AKAR KARYA DEWI LESTARI
}

\author{
Triesna Fuji Hatma
}

\begin{abstract}
This study aims to find out, how the analysis of bilingualism on Supernova novel Akar by Dewi Lestari specifically examine 1) How is the form of switch code on Novel Supernova Akar by Dewi Lestari 2) How is the form of mixed code on Novel Supernova Akar by Dewi Lestari 3) How the function context of switch code on Novel Supernova Akar by Dewi Lestari 4) How the function context of mixing code on Novel Supernova Akar by Dewi Lestari. The research data in the form of words in the novel Supernova Akar by Dewi Lestari and the source data used in this study is novel literary work entitled Supernova Akar by Dewi Lestari. The method used in this research is descriptive method. Data collection techniques used are documentation and recording techniques. The products of this research isthe use of bilingualism in Novel Supernova Akar by Dewi Lestari, formof switch codethat is used by a speaker and two speakers, mixed forms are used in order to cool the code, follow the trend, educational exhibit, showing the position and function of the context of the use of switch code and mixed code that is a) transactional function, namely the function of language to tell something to the listener ( to do something), and b) interactional function is linguistic function to maintenance social relathionship, example to negociate role relations, people with the same age solidarity, ship exchange on conversation, saving face to speaker or listener.
\end{abstract}

Key words : The Analysis, bilingualism, Novel, Supernova

\section{Pendahuluan}

Bahasasebagai alat untuk berkomunikasi, berfungsi untuk menyampaikan pikiran, gagasan, konsep dan perasaan. Bahasa digunakan manusia disegala bidang kehidupan untuk menjalankan segala aktivitas. Oleh karena itu, bahasa merupakan alat komunikasi terpenting bagi manusia.

Dalam suatu masyarakat bahasa, bahasa itu menjadi beragam dan bervariasi, terjadinya keragaman atau kevariasian bahasa ini bukan hanya disebabkan oleh penuturnya yang heterogen, melainkan juga karena interaksi sosial yang mereka lakukan sangat beragam. Keragaman ini akan luas kalau bahasa tersebut digunakan oleh penutur yang sangat banyak, serta dalam wilayah yang sangat luas.

Pengarang (penulis sastra) tentu mempunyai variasi bahasa tersendiri dalam menyampaikan ceritanya kepada pembaca. Secara langsung jelas bahwa erat sekali hubungan antara bahasa dengan karya sastra.

Karya sastra merupakan hasil karya seorang pengarang dalam bentuk genre sastra. Genresastra yang umum dikenal adalah puisi, prosa, dan drama.Salah satu genre sastra yang berbentuk prosa adalah novel. Novel merupakan salah satu bentuk karya sastra dalam bentuk tulisan. Karena novel merupakan cerita dalam ukuran luas, seorang pengarang harus mempunyai variasi bahasa tersendiri dalam menuangkan idenya kepada pembaca.

Salah satu karya sastra novel yaituSupernova Akar Karya dari pengarang Dewi Lestari yang diterbitkan pada tahun 2002, seperti novel-novel pada umumnya, Supernova Akar berisi tentang rangkaian cerita petualangan 
kehidupan seseorang dalam mencari kesejatian, tetapi yang menjadi alasan penulis ingin meneliti novel Supernova Akarkarena didalam novel tersebut terdapat peristiwa bilingualisme atau kedwibahasaan dalam bentuk alih kode serta campur kode, dengan harapan hasil penelitian AnalisisBilingualisme pada Novel Supernova Akar Karya Dewi Lestari ini dapat bermanfaat untuk penelitian tentang bahasa dalam karya sastra.

Berdasarkan latar belakang di atas, maka yang menjadi masalah umum dalam penelitian iniadalah bagaimana penggunaan bilingualismepada Novel Supernova Akarkarya Dewi Lestari, sedangkan secara khusus yang menjadi batasan masalah dalam penelitian ini adalah :

a) Bagaimana bentuk alih kode dalam novel Supernova Akar karya Dewi lestari?

b) Bagaimana bentuk campur kode dalam novel Supernova Akar karya Dewi lestari?

c) Bagaimana fungsi konteks bentuk alih kode dalam novel Supernova Akar karya Dewi lestari?

d) Bagaimana fungsi konteks bentuk campur kode dalam novel Supernova Akar karya Dewi lestari?

Berdasarkan rumusan masalah di atas maka tujuan penelitian ini adalah sebagai berikut :

1. Mendeskripsikan bentuk alih kode bahasa dalam novel Supernova Akar karya Dewi Lestari.

2. 2) Mendeskripsikan bentuk campur kode bahasa dalam novel Supernova Akar karya Dewi Lestari.

3. Mendeskripsikan fungsikonteks dari penggunaanbentuk alih kode bahasa novel Supernova Akar karya Dewi Lestari.
4. Mendeskripsikan fungsi konteks dari penggunaanbentuk campur kode bahasa novel Supernova Akar karya Dewi Lestari.

Penelitian ini diharapkan dapat memberikan manfaat, baik secara teoretis maupun praktis, yaitu :

1. Manfaat Teoretis

Penelitian ini diharapkan mampu memberikan wawasan dan memperkaya khazanah ilmu pengetahuan mengenai hubungan sosiolinguistik dengan bahasa sastra(novel). Selain itu penelitian ini diharapkan mampu memberikan sumbangan kepada pengajaran bahasa Indonesia terutama di bidang sosiolinguistik.

2. Manfaat Praktis

Secara praktis dengan penelitian ini diharapkan dapat membantu pembaca untuk lebih memahami penggunaan bahasa dalam novel Supernova Akar karya Dewi Lestari terutama penggunaan bilingualisme dengan pemanfaatan disiplin ilmu sosiolinguistik.

Teori yang digunakan dalam penelitian ini adalah teori sosiolinguistik. Fishman (dalam Chaer, 1995: 6) mendefinisikan Sosiolinguistik sebagai kajian tentang ciri khas variasi bahasa, fungsi-fungsi variasi bahasa, fungsi-fungsi variasi bahasa, dan pemakai karena ketiga unsur ini selalu berinteraksi, berubah, dan saling mengubah satusama lain dalam suatu masyarakat tutur. Lebih lanjutChaer (1995: 3) mengatakan bahwa sosiolinguistik adalah bidang ilmu antardisiplin yang mempelajari bahasa dalam kaitannya dengan penggunaan bahasa itu di dalam masyarakat. Hal ini dipertegas dengan pendapat Nababan (1993: 2) yang mengungkapkan bahwa sosiolinguistik itu mempelajari dan membahas aspek-aspek kemasyarakatan 
bahasa, khususnya perbedaan (variasi) yang terdapat dalam bahasa yang berkaitan dengan faktor-faktor kemasyarakatan (sosial).

Dari beberapa pendapat para ahli di atas, dapat disimpulkan bahwa pengertian sosiolinguistik tidak terlepas dari persoalan hubungan bahasa dengan kegiatan-kegiatan atau aspek-aspek dalam suatu masyarakat pengguna bahasa atau masyarakat tutur khususnya perbedaan (variasi) yang terdapat dalam bahasa.

Pada masyarakat tutur yang terbuka, artinya yang mempunyai hubungan dengan masyarakat tutur lain, tentu akan mengalami apa yang disebut dengan kontak bahasa dengan segala peristiwa-peristiwa kebahasaan sebagai akibatnya. Peristiwa yang mungkin terjadi sebagai akibat adanya kontak dua bahasa itu adalah apa yang didalam sosiolinguistik disebut bilingualisme.

Jadi dapat ditarik kesimpulan bahwa bilingualisme adalah penggunaan dua bahasa atau kedwibahasaan dalam berinteraksi dengan orang lain. Sedangkan kemampuan untuk menggunakan dua bahasa disebut bilingualitas. Orang yang dapat menggunakan kedua bahasa itu disebut orang yang bilingual.

Dalam bilingualisme atau kedwibahasaan, peristiwa yang lazim terjadi sebagai akibat adanya kontak bahasa itu adalah alih kode dan campur kode. Hal ini dipertegas oleh pendapat Nababan (1984: 6) bahwa dalam topik kedwibahasaan, dibicarakan juga alih kode dan campur kode.

Pemakaian bahasa dalam konteks oleh penutur/penulis, lebih memperhatikan hubungan antara penutur dan ujarannya. Beberapa unsur bahasa yang paling jelas yang memerlukan informasi kontekstual, untuk menafsirkan unsur-unsur itu kita perlu mengetahui (sekurang-kurangnya) siapa penutur dan pendengarnya, dan waktu serta tempat produksi wacana itu (Yule, 1996: 27).

Hymes (dalam Yule, 1996: 39) berpendapat ciri-ciri konteks meliputi saluran(bagaimana hubungan antara para peserta dalam peristiwa dipeliharadengan wicara, tulisan, tanda-tanda, tanda-tanda asap), kode(bahasa, dialek atau gaya bahasa apa yang dipakai), bentuk pesan(bentuk apa yang dimaksudkan-obrolan, perdebatan, khotbah, dongeng, soneta, surat cinta, dsb.), peristiwa (sifat peristiwa yang komunikatif yang di dalamnya mungkin disisipkan suatu genre-jadi khotbah atau doa mungkin merupakan bagian dari peristiwa yang lebih besar, kebaktian di gereja), kemudian Hymes menambahkan ciri-ciri lain, misalnya kunci (yang melibatkan evaluasi-apakah itu khotbah yang baik, keterangan yang menyedihkan, dsb.), dan tujuan(apa yang dimaksudka para peserta sebaiknya terjadi sebagai hasil peristiwa komunikatif).

Jadi dapat disimpulkan bahwa konteks penggunaan bahasa terdiri dari siapa yang berbicara, dimana, kapan, dan apa tujuan dari pembicaraan tersebut. Yule(1996: 1-3) membedakan fungsi bahasa menjadi dua yakni fungsi bahasa untuk menyampaikan informasi disebut dengan fungsi transaksional, sedangkan fungsi bahasa yang terlibat dalam pengungkapan hubungan-hubungan sosial dan sikap-sikap pribadi disebut dengan fungsi interaksional. Fungsi transaksional adalah fungsi bahasa yang paling utama yakni menyampaikan 
informasi antara si pembicara dan pendengar. Fungsi interaksional lebih memperhatikan pemakaian bahasa dalam memelihara hubungan-hubungan sosial misalnya untuk merundingkan relasi-relasi peran, solidaritas orangorang sebaya, tukar menukar giliran dalam percakapan, penyelamatan muka baik di pihak pembicara maupun dipihak pendengar.

Jadi, dapat disimpulkan bahwa selain berfungsi sebagai alat komunikasi, fungsi bahasa yang paling penting adalah penyampaian informasi. Fungsi bahasa yang dipakai untuk memberitahukan sesuatu kepada pendengar atau menyuruhnya melakukan sesuatu itu disebut dengan fungsi transaksional, ditentukan oleh konteks, yakni siapa yang berbicara, kepada siapa, dimana, bilamana, bagaimana, dan apa fungsi ujaran itu.

Novel adalah salahsatu jenis karya sastra yang berbentuk prosa. Kata novel berasal dari bahasa latin novellas yang diturunkan pula dari kata novies yang berarti baru. Dikatakan baru karena novel adalah bentuk karya sastra yang datang dari sastra lainnya seperti puisi dan drama. Novel juga diartikansebagai suatu karangan atau karya sastra yang lebih pendek dari roman, tetapi jauh lebih panjangdaripada cerita pendek, yang isinya hanya mengungkapkan suatu kejadian yang penting, menarikdari kehidupan seseorang (dari suatu episode kehidupan seseorang) secara singkat dan yang pokok-pokoknya saja.

Juga perwatakan pelakupelakunya digambarkan secara garis besar saja, tidak sampai pada masalah yang sekecil-kecilnya. Dan kejadian yang digambarkan itu mengandung suatu konflik jiwa yang mengakibatkan adanya perubahan nasib.

Dari beberapa pengertian di atas dapat disimpulkan bahwa novel adalah karangan prosa yang mengandung rangkaian cerita yang panjang tentang kehidupan seseorang dengan orangorang disekelilingnya, dalam ukuran luas yaitu alur yang kompleks, suasana cerita yang beragam, karakter tokoh yang banyak, tema yang kompleks, setting yang beragam.

Menurut Tarigan (1985: 170) ciriciri novel adalah jumlah kata pada novel lebih dari 35.000 kata, jumlah halaman novel minimal 100 halaman kuarto, jumlah waktu rata-rata yang digunakan untuk membaca novel minimal 2 jam atau 120 menit, novel yang tergantung pada pelaku mungkin lebih dari satu pelaku, novel menyajikan lebih dari satu impresi efek dan emosi, skala novel lebih luas, intensitas kurang diutamakan dan kelajuan novel kurang tepat.

Seperti karya sastra lainnya, novel juga memiliki jenis.Novel dapat dibedakan berdasarkan isi cerita dan mutu novel.Dalam dunia kesusasteraan sering ada usaha untuk mencoba membedakan antara novel serius dan novel populer (Nurgiantoro 2010: 17). Dari pendapat tersebut, Nurgiantoro jelas mengkategorikan novel menjadi dua jenis yaitu, novel populer dan novel serius. Novel populer adalah jenis novel yang kebanyakan diminati oleh remaja hal ini dikarenakan, novel populer menyuguhkan problema kehidupan yang berkisar pada cerita asmara yang simpel dan bertujuan untuk menghibur. Sedangkan isi cerita dalam novel serius membahas masalah-masalah kehidupan kemanusiaan yang diungkapkan pengarangnya. 


\section{METODE PENELITIAN}

Menurut Badudu (1996: 46), data adalah bukti yang ditemukan dari hasil penelitian yang dapat dijadikan dasar kajian atau pendapat. Data dalam penelitian ini adalah dokumen historis, yakni pikiran Dewi Lestari yang di tuangkan melalui kata-kata dalam novel Supernova Akar Karya Dewi Lestari.

Sumber data yang digunakan dalam penelitian ini adalah karya sastra novel yang berjudul Supernova Akarkarya Dewi Lestari yang diterbitkan pada tahun 2002, berjumlah 256 halaman yang diterbitkan di Yogyakarta oleh Bentang Pustaka.

Teknik pengumpulan data yang digunakan dalam penelitian ini adalah :

1. Teknik dokumentasi

Menurut Hikmat (2011: 83) teknik studi dokumentasi adalah pelusuran dan perolehan data yang diperlukan melalui data yang telah tersedia.Dokumen merupakan catatan peristiwa yang sudah berlalu.Dokumen bisa berbentuk gambar, karya-karya monumental dari seseorang, atau tulisan/ teks (misalnya: novel, cerpen, puisi, dan lain-lain). Dokumen yang digunakan dalam penelitian ini yaitu berupa teks novel Supernova Akar Karya Dewi Lestari.

2. Teknik pencatatan

$$
\text { Moleong }
$$

(2007:

berpendapat bahwa dalam melakukan pengamatan tidak bisa berdiri sendiri, artinya tidak dapat dilakukan tanpa pencatatan datanya. Catatan itu dibuat dalam bentuk kata-kata kunci, singkatan, pokok-pokok utama saja. Dalam hal ini catatan yang dimaksud adalah mencatat kata-katayang menggunakan bentuk alih kode dan campur kode dalam Novel Supernova Akar Karya Dewi Lestari.
Analisis data dalam penelitian ini menggunakan pendekatan kualitatif, dengan langkah-langkah sebagai berikut :

1. Membaca teks novel Supernova Akarkarya Dewi Lestari.

2. Membuat tabulasi data yang menggunakan bentuk alih kode dan campur kode serta fungsi konteks penggunaan bentuk alih kode dan campur kodedalam novel Supernova Akarkarya Dewi Lestari.

3. Mengklasifikasi hasiltabulasi atas penggunaan bentuk alih kode dan campur kode serta fungsi kontekspenggunaan bentuk alih kode dan campur kode dalam novel Supernova Akarkarya Dewi Lestari.

4. Menginterpretasikan data didasarkan pada penggunaan bentuk alih kode dan campur kode serta fungsikonteks penggunaan bentuk alih kode dan campur kode dalam novel Supernova Akarkarya Dewi Lestari.

5. Penyajian hasil penelitian Alih kode dan campur kode serta fungsi konteks penggunaan alih kode dan campur kode dalam novel Supernova Akarkarya Dewi Lestari.

6. Menarik kesimpulan.

\section{Hasil dan Pembahasan}

Novel Supernova Akar merupakan salah satu karya Dewi Lestari yang bercerita tentang seorang anak manusia bernama Bodhi yang mencari kesejatian hidup. Bodhi dibesarkan di Vihara Pit Yong Kiong. Bodhi kemudian dipungut, diasuh, dan dididik oleh seorang Pandita, Guru Liong.

Penelitian ini bersifat kualitatif, sehingga sangat diperlukannya deskripsi kata-kata untuk menyampaikan hasil temuannya. Sebelum membahas data 
penelitian, dirasa penting untuk mendeskripsikan temuan penelitian. Temuan penelitian berupa data kualitatif, yakni kutipan kalimat percakapan yang ada pada novel Supernova Akar karya Dewi Lestari. Dalam novel tersebut ada hal yang menarik untuk dikaji, yaitu penggunaan bilingualisme dalam bentuk alih kode dan campur kode.

1. Penggunaan Alih Kode

Penggunaan Alih Kode serta Fungsi Konteks Penggunaan Alih Kode pada Novel Supernova Akar Karya Dewi Lestari:

a. Bentuk Penggunaan Alih Kode Seorang Penutur :

1) Berikut adalah peristiwa percakapan di mana seorang penutur menggunakan alih kode :

Penutur I (Tristan): "This our everharging bible, Bodhi. Nothing dogmatic "ia tertawa.

Penutur I (Tristan): "so, siap-siap melepaskannya kapan saja. And, uh, coba pertimbangkan untuk mengganti tas nenek-nenek itu." (SN AK 1.1)

\section{Dalam kutipan tersebut Tristan} yang berasal dari Australia yang merupakan teman Bodhi yang berasal dari Indonesia pada awalnya menggunakan kode bahasa Indonesia kemudian ia menggunakan kode bahasa Inggris dalam percakapannya dengan Bodhi, peristiwa percakapan tersebut terjadi di Stasiun Hua Lampong, pada percakapan tersebut Tristan yang ingin menyampaikan nasihat melalui gurauan canda untuk sahabatnya Bodhi sebelum mereka berpisah agar Bodhi tidak lagi menggunakan tasnya lagi, karena bagi
Tristan tas yang dipakai Bodhi sangatlah jelek.

b. Bentuk Penggunaan Alih Kode Dua Orang Penutur

1) Berikut ini peristiwa percakapan penggunaan alih kode oleh dua orang penutur :

Penutur I (Bodhi) : Aku menelan ludah. "Ma-maaf, saya benar-benar tidak tahu."

Penutur II (Epona):"Where are you from?"

Penutur I (Bodhi) :"Indonesia."

Tangannya seketika berhenti kerja. la melirikku.

Penutur II (Epona): "You're a tourist?" Aku mengangguk.

Penutur II (Epona): "Here? In Pilin?” la tertawa sinis. "Next time, get a different travel agent."

Penutur I (Bodhi) : "I was looking for a friend," jelasku.

Penutur II (Epona):“Next time, try another social circle."

Aku terdiam. Setelah sekian lama, baru kuberanikan diri untuk bertanya.

Penutur I (Bodhi) "Nama kamu siapa?"

Penutur II (Epona):“Epona O'Leary. I'm a deminer. Working for CMAC."(SN AK 2.8)

$$
\text { Pada kutipan percakapan }
$$
tersebut Penutur I (Bodhi) yang merupakan orang Indonesia pada awalnya menggunakan bahasa Indonesia beralih kode ke bahasa Inggris, karena ia berbicara dengan Penutur II (Epona) seorang wanita berkebangsaan Prancis. Epona bertanya menggunakan bahasa Inggris sehingga Bodhi menjawab juga dengan menggunakan Bahasa Ingris. 
2) Penggunaan Campur Kode

Penggunaan Campur Kode serta Fungsi Konteks Penggunaan Campur Kode pada Novel Supernova Akar Karya Dewi Lestari:

a. Bentuk Penggunaan Campur Kode Agar Keren

Penutur (Star) : "Good, ini uangnya, saya bayar dimuka. Kapan saya bisa ditato?"(SN CK AK.4)

Pada kutipan tersebut dapat dilihat si penutur menggunakan campur kode Bahasa Inggris ke dalam bahasa Indonesia agar terlihat keren si penutur menggunakan kata good, si penutur bermaksud menyatakan bahwa dia ingin ditato oleh Bodhi yang merupakan seorang tatois pemula dengan membayar dahulu dimuka tanpa tahu bagaimana hasil tato yang akan digambarkan oleh Bodhi.

b. Bentuk Penggunaan Campur Kode Mengikuti trend

Penutur (Bodhi) : Saya harus Check-out dari sini"(SN CK T.6)

Pada kutipan tersebut si penutur menggunakan campur kode bahasa Inggris ke dalam bahasa Indonesia, si penutur menggunakan kata check out sebagai ganti kata keluar, karena kata tersebut sangat trend digunakan dibandingkan menggunakan kata keluar, si penutur bermaksud ingin keluar dari hotel tempat si penutur menginap.

c. Bentuk Penggunaan Campur Kode Memamerkan Pendidikan

Penutur (Kell) : "Untuk optimisme, saya beri angka sepuluh setengah. Look, 'garpu' rusakmu belum sepenuhnya tersamarkan. Ini butuh teknik yang lain, pengisian warna dan shading." (SN CK P.1)

Pada kutipan tersebut si penutur menggunakan campur kode bahasa Inggris ke dalam bahasa Indonesia, si penutur menggunakan kata-kata look dan shading, dari percakapan tersebut si penutur bermaksud menjelaskan bagaimana teknik dalam membuat tato, dari hal tersebut dapat dilihat bahwa si penutur ingin memamerkan pengetahuannya tentang teknik melukis tato.

d. Bentuk Penggunaan Campur Kode Memamerkan kedudukan

Penutur (Star) : "Ah let me see, darah saya ini pertemuan Timur Tengah dan Eropa Timur, saya tinggal di negeri dongeng-" (SN CK KD.2)

Pada kutipan tersebut si penutur menggunakan campur kode bahasa Inggris ke dalam Bahasa Indonesia, si penutur menggunakan Ah let me see, dalam percakapan tersebut adalah si penutur bermaksud memamerkan kepada lawan tuturnya bahwa si penutur mempunyai darah campuran dari Timur Tengah dengan darah Eropa.

3) Fungsi Konteks Penggunaan Alih Kode

a) Fungsi Konteks Bentuk Penggunaan Alih Kode Seorang Penutur

Penutur I (Tristan) : "This our ever-harging bible, Bodhi. Nothing dogmatic " ia tertawa.

Penutur I (Tristan): "so, siap-siap melepaskannya kapan saja. And, 
uh, coba pertimbangkan untuk mengganti tas nenek-nenek itu."

(SN AK 1.1)

\begin{abstract}
Dalam kutipan tersebut Tristan yang berasal dari Australia yang merupakan teman Bodhi yang berasal dari Indonesia pada awalnya menggunakan kode bahasa Indonesia kemudian ia menggunakan kode bahasa Inggris dalam percakapannya dengan Bodhi, peristiwa percakapan tersebut terjadi di Stasiun Hua Lampong, fungsi dari konteks percakapan tersebut adalah Tristan yang ingin menyampaikan nasihat untuk sahabatnya Bodhi sebelum mereka berpisah agar Bodhi tidak lagi menggunakan tasnya lagi, karena bagi Tristan tas yang dipakai Bodhi sangatlah jelek.
\end{abstract}

Dari kutipan percakapan tersebut, fungsi konteks dari penggunaan campur kode tersebut adalah fungsi transaksional, fungsi yang digunakan untuk menyampaikan informasi kepada lawan tutur.

\section{b) Fungsi Konteks Bentuk Penggunaan Alih Kode Dua Orang Penutur}

Penutur I (Bodhi) : Aku menelan ludah. "Ma-maaf, saya benar-benar tidak tahu." Penutur II (Epona):"Where are you from?"

Penutur I (Bodhi) :"Indonesia."

Tangannya seketika berhenti kerja. la melirikku.

Penutur II (Epona): "You're a tourist?" Aku mengangguk.

Penutur II (Epona): "Here? In Pilin?" la tertawa sinis. "Next time, get a different travel agent."
Penutur I (Bodhi) : "I was looking for a friend," jelasku.

Penutur II (Epona): "Next time, try another social circle."

Aku terdiam. Setelah sekian lama, baru kuberanikan diri untuk bertanya.

Penutur I (Bodhi) "Nama kamu siapa?"

Penutur II (Epona): "Epona O'Leary. I'm a deminer. Working for CMAC."(SN AK 2.1)

Pada kutipan percakapan tersebut Penutur I (Bodhi) yang merupakan orang Indonesia pada awalnya menggunakan bahasa Indonesia beralih kode ke bahasa Inggris, karena ia berbicara dengan Penutur II (Epona) seorang wanita berkebangsaan Prancis. Epona bertanya menggunakan bahasa Inggris sehingga Bodhi menjawab juga dengan menggunakan Bahasa Ingris. Fungsi konteks penggunaan alih kode pada percakapan tersebut adalah untuk menyampaikan informasi antara kedua pembicara yang berbeda bahasa.

Dari percakapan tersebut fungsi konteks dari penggunaan alih kode oleh dua orang penutur tersebut adalah Fungsi interaksional lebih memperhatikan pemakaian bahasa dalam memelihara hubungan-hubungan sosial misalnya untuk merundingkan relasi-relasi peran, solidaritas orangorang sebaya, tukar menukar giliran dalam percakapan, penyelamatan muka baik pembicara maupun pendengar.

4) Fungsi Konteks Penggunaan Campur Kode

a. Fungsi Konteks Bentuk Penggunaan Campur Kode agar keren 
Penutur (Kell) : "She's probably checking in to The Oriental by now. Atau pulang ke Hollywood." (SN CK K.2)

Pada kutipan tersebut si penutur menggunakan campur kode Bahasa Inggris ke dalam Bahasa Indonesia, si penutur menggunakan campur kode tersebut agar terlihat keren di depan lawan bicaranya, fungsi konteks dari percakapan tersebut adalah memberikan informasi bahwa Star sudah pergi meninggalkan Thailand untuk kembali ke Negara Asalnya Hollywood Amerika.

\section{b. Fungsi Konteks Bentuk Penggunaan Campur Kode mengikuti Trend}

Penutur (Bodhi) : "No can do" aku menolak."Kamu bukan Departemen sosial dan saya tidak setragis itu. I'm out of here."(SN CK T.3)

Pada kutipan tersebut si penutur menggunakan campur kode bahasa Inggris ke dalam Bahasa Indonesia, si penutur menggunakan kata No can do dan I'm out of here, penutur menggunakan kata tersebut mengikuti trend, karena si penutur bisa menggunakan kata-kata tidak dapat melakukannya sebagai ganti kata No can do, dan kata saya keluar dari sini sebagai ganti kata I'm out of here, fungsi konteks penggunaan campur kode dalam percakapan tersebut adalah si penutur bermaksud mengatakan bahwa dia tidak ingin tinggal lebih lama lagi di penginapan itu, walaupun lawan petuturnya itu bermaksud menolongnya dan memperbolehkannya untuk menginap di penginapan itu lebih lama. c. Fungsi Konteks Bentuk Penggunaan Campur Kode Memamerkan Pendidikan

Penutur I Kell "Oke, khusus untuk shading, ada ilmu tersendiri. Science of light and dark,"(SN CK P.2)

Pada kutipan tersebut si penutur menggunakan campur kode bahasa Inggris ke dalam Bahasa Indonesia, si penutur menggunakan kata Science of light and dark yang berarti pengetahuan tentang ilmu terang dan gelap, pada percakapan tersebut si penutur menggunakan campur kode untuk memamerkan pengetahuannya tentang tato.

d. Fungsi Konteks Bentuk Penggunaan Campur Kode Memamerkan Kedudukan

Penutur (Star) : "Ah let me see, darah saya ini pertemuan Timur Tengah dan Eropa Timur, saya tinggal di negeri dongeng-"(SN CK KD.1)

Pada kutipan tersebut si penutur menggunakan campur kode bahasa Inggris ke dalam Bahasa Indonesia, si penutur menggunakan Ah let me see, fungsi konteks penggunaan campur kode dalam percakapan tersebut adalah si penutur bermaksud memamerkan kepada lawan tuturnya bahwa si penutur mempunyai darah campuran dari Timur Tengah dengan darah Eropa.

Dari beberapa percakapan bentuk campur kode di atas dapat disimpulkan fungsi konteks sebagai berikut :

1. Fungsi transaksional, yakni fungsi bahasa yang paling utama yakni menyampaikan informasi antara si pembicara dan pendengar. 
2. Fungsi interaksional, yaitu fungsi bahasa yang lebih memperhatikan pemakaian bahasa dalam memelihara hubungan-hubungan sosial misalnya untuk merundingkan relasi-relasi peran, solidaritas orang-orang sebaya, tukar menukar giliran dalam percakapan, penyelamatan muka baik pembicara maupun pendengar.

Pada novel Supernova Akar karya

Dewi Lestari banyak terdapat percakapan yang berupa alih kode yang dilakukan oleh seorang penutur sebanyak 13 (tiga belas) peristiwa percakapan yang dibahas dalam hasil penelitian pada halaman 34 (tiga puluh empat) dan alih kode yang dilakukan dua orang penutur sebanyak 18 (delapan belas) peristiwa percakapan yang dibahasdalam hasil penelitian pada halaman 36 (tiga puluh enam) .

Dalam Novel Supernova Akar karya Dewi Lestari juga terdapat penggunaan campur Kode Bahasa Inggris ke dalam Bahasa Indonesia. Campur kode ialah bilamana orang mencampur dua bahasa atau ragam bahasa dalam suatu tindak bahasa.

Campur kode biasanya digunakan dalam suatu pergaulan karena sedang menjadi trend agar si pembicara menjadi menjadi keren, selain itu campur kode dilakukan si pembicara untuk memamerkan "keterpelajarannya" atau "kedudukannya". Pada Novel Supernova Akar Karya Dewi Lestari terdapat peristiwa campur kode biasanya digunakan dalam suatu agar si pembicara menjadi menjadi keren sebanyak 20 (dua puluh) peristiwa percakapan yang di bahas dalam hasil penelitian pada halaman 38 (tiga puluh delapan) dan mengikuti trend sebanyak 43 (empat puluh tiga) peristiwa percakapan yang dibahas dalam hasil penelitian pada halaman 40 (empat puluh), selain itu campur kode dilakukan si pembicara untuk memamerkan pendidikan atau keterpelajarannya sebanyak 19 (sembilan belas) yang dibahas dalam hasil penelitian pada halaman 41 (empat puluh satu) dan peristiwa campur kode yang memamerkan kedudukannya sebanyak 6 (enam) peristiwa percakapan yang dibahas dalam hasil penelitian pada halaman 42 (empat puluh dua).

Fungsi dari penggunaan alih kode dan campur kode dalam novel Supernova Akar karya Dewi Lestari adalah a) fungsi transaksional, yaitu fungsi bahasa untuk menyampaikan informasi (untuk memberitahukan sesuatu atau menyuruh melakukan sesuatu), dan b) fungsi interaksional, fungsi bahasa yang lebih memperhatikan pemakaian bahasa dalam memelihara hubungan-hubungan sosial misalnya untuk merundingkan relasi-relasi peran, solidaritas orang-orang sebaya, tukar menukar giliran dalam percakapan, penyelamatan muka baik pembicara maupun pendengar.

\section{Simpulan}

Berdasarkan hasil analisis dan pembahasan terhadap novel Supernova Akar Karya Dewi Lestari dalam penelitian ini dapat disimpulkan sebagai berikut:

1. Bentuk alih kodemencakup penggunaanalih kode oleh seorang penuturdan penggunaan alih kode oleh dua orang penutur dalam Bahasa Inggris ke Bahasa Indonesia atau sebaliknyadalam beberapa peristiwa percakapan.

2. Bentukcampur kode mencakup penggunaan campur kode bahasa Inggris ke dalam bahasa 
Indonesia,agar si pembicara menjadi menjadi keren, mengikuti trend selain itu campur kode dilakukan si pembicara untuk memamerkan pendidikan atau keterpelajarannya, peristiwa campur kode yang memamerkan kedudukannyadalam beberapa peristiwa percakapan.

3. Fungsi konteks penggunaan bentukalih kode meliputi a) fungsi transaksional, yaitu fungsi bahasa untuk menyampaikan informasi (menyuruh atau melakukan sesuatu) dan b) fungsi interaksional, yaitu fungsi bahasa dalam memelihara hubunganhubungan sosial misalnya untuk merundingkan relasi-relasi peran, solidaritas orang-orang sebaya, tukar menukar giliran dalam percakapan, penyelamatan muka baik pembicara maupun pendengar.

4. Fungsi konteks dari penggunaan bentukcampur kode meliputi a) fungsi transaksional, yaitu fungsi bahasa untuk menyampaikan informasi (menyuruh atau melakukan sesuatu) dan b) fungsi interaksional, yaitu fungsi bahasa dalam memelihara hubungan-hubungan sosial misalnya untuk merundingkan relasi-relasi peran, solidaritas orang-orang sebaya, tukar menukar giliran dalam percakapan, penyelamatan muka baik pembicara maupun pendengar.

\section{Saran}

Penulis menyadari penelitian ini masih belum sempurna, kiranya penelitian ini dapat berguna nantinya bagi :

1. Pembaca karyasastra novel agar dapat menambah wawasan penggunaan bahasa dalam karya sastra novel khususnya bilingualisme bentuk alih kode dan campur kode.

2. Pembaca karya sastra novel, hal ini penting karena dapat menambah pengetahuan mengenai fungsi konteks penggunaan bahasa dalam karya sastra novel .

3. Sebagai calon guru bidang studi Bahasa Indonesia kita harus banyak membaca karya sastra novel, tidak hanya menambah pengetahuan mengenai karya sastra tetapi juga pengetahuan mengenai penggunaan bahasa dalam karya sastra khususnya novel.

\section{Daftar Pustaka}

Alwasilah, Chaedar. 1989. Sosiologi Bahasa. Bandung: Angkasa.

Chaer, Abdul. Dkk. 1991. Sosiolinguistik Perkenalan Awal. Jakarta: Rineka Cipta.

Halim, Abdul. 2011. Metodologi Penelitian Bahasa. Jakarta: Diadit Media Press.

Keraf, Gorys. 1981. Diksi dan Gaya Bahasa. Jakarta: Gramedia Pustaka Utama.

Kosasih. 2012. Dasar-dasar Keterampilan Bersastra Bandung : Yrama Widya.

Kridalaksana, Harimurti. 2010. Kamus Linguistik. Jakarta: Gramedia Pustaka Utama.

Lestari, Dewi.2002. Supernova(Akar). Bandung: Trudee Books.

Mahsun. 2005. Metode Penelitian Bahasa : Tahapan Strategi, Metode, dan Tekniknya. Jakarta: Grafindo Persada. 
Moleong, Lexy.K. 2007. Metode Penelitian Kualitatif. Bandung: Remaja Rosda Karya.

Nababan, P.W.J. 1984. Sosiolinguistik Suatu Pengantar. Jakarta: Gramedia.

Nurgiyantoro, Burhan. 2010. Teori Pengkajian Fiksi. Yogyakarta: Gajah Mada University Press.

Pateda, Mansoer. 1987. Sosiolinguistik. Bandung: Angkasa.

Pusat Pembinaan dan Pengembangan Bahasa. 2003. Kamus Besar Bahasa Indonesia. Jakarta: Balai Pustaka.

Rahardi, Kunjana. 2001. Sosiolinguistik, Kode dan Alih Kode. Yogyakarta: Pustaka Pelajar.

Samsuri. 1987. Analisis Bahasa. Jakarta: Erlangga.

Sudaryanto. 1994. Pemanfaatan Potensi Bahasa. Yogyakarta: Gadjah Mada University Press.
Susetyo. 2009. Menulis Akademik. Bengkulu: FKIP Universitas Bengkulu.

Sumarsono dan Paina Pertama. 2002. Sosiolinguistik. Yogyakarta: Sabda dan Pustaka Belajar.

Suwito. 1983.Sosiolinguistik: Terapan dan Problema. Solo: Henari Offse.

Syukur, Abdul. 1995. Sosiolinguistik. Surabaya: Usaha Nasional.

Tarigan, Henry Guntur. 1986. Pengajaran Kedwibahasaan. Bandung: Angkasa.

Wahyuningtyas, Sri dan Wijaya Heru. 2010. Pengantar Apresiasi Prosa. Surakarta: Yuma Pustaka.

Yule, George dkk. 1996. Analisis Wacana. Jakarta: Gramedia Pustaka Utama. 